\title{
Change in snow depletion pattern in a river basin of Arunachal Pradesh under projected climatic scenarios
}

\author{
Mishra P. ${ }^{1}$, Bandyopadhyay A. ${ }^{2,}{ }^{*}$ and Bhadra A. ${ }^{2}$ \\ Arunachal Pradesh 791109, India. \\ Arunachal Pradesh 791109, India. \\ Received: 24/04/2015, Accepted: 07/03/2017, Available online: 28/03/2017 \\ *to whom all correspondence should be addressed: \\ e-mail: arnabbandyo@yahoo.co.in
}

${ }^{1}$ Research Scholar, Department of Agricultural Engineering, North Eastern Regional Institute of Science and Technology, Nirjuli (Itanagar),

${ }^{2}$ Associate Professor, Department of Agricultural Engineering, North Eastern Regional Institute of Science and Technology, Nirjuli (Itanagar),

\section{Abstract}

Snow depletion curves (SDCs) are important in hydrological studies for predicting snowmelt generated runoff in high mountain catchments. The present study deals with the derivation of the average snow depletion pattern in the Mago basin of Arunachal Pradesh, which falls in the eastern Himalayan region and the generation of climate affected SDCs in future years (2020, 2030, 2040, and 2050) under different projected climatic scenarios. The MODIS daily snow cover product at $500 \mathrm{~m}$ resolution from both the Aqua and Terra satellites was used to obtain daily snow cover maps. MOD10A1 and MYD10A1 images were compared to select cloud free or minimum cloud image to obtain the temporal distribution of snow cover area (SCA). Snow accumulation and depletion patterns were obtained by analysing SCA at different days. For most of the years, two peaks were observed in the SCA analysis. The conventional depletion curve $(C D C)$ representing present climate was derived by determining and interpolating the SCA from cloud-free (cloud<5\%) images for the selected hydrological year 2007. The investigation shows that the SCA was highest in February and lowest in May. Ten years meteorological data were used to normalize the temperature and precipitation data of the selected hydrological year (2007) to eliminate the impact of their yearly fluctuations on the snow cover depletion. The temperature and precipitation changes under four different projected climatic scenarios (A1B, A2, B1, and IPCC Commitment) were analysed for future years. Changes in the cumulative snowmelt depth with respect to the present climate for different future years were studied by a degreeday approach and were found to be highest under A1B, followed by $A 2, B 1$, and IPCC Commitment scenarios. It was observed that the $A 1 B$ climatic scenario affected the depletion pattern most, making the depletion of snow to start and complete faster than under different scenarios.
Advancing of depletion curve for different future years was found to be highest under A1B and lowest under IPCC Commitment scenarios with $\mathrm{A} 2$ and $\mathrm{B} 1$ in-between them.

Keywords: MODIS, Snow-cover depletion curve (SDC), snowcovered area (SCA), cumulative snowmelt depth, projected climatic scenarios, Eastern Himalayan region.

\section{Introduction}

Snow cover area (SCA) and snowmelt have an important role in the hydrological response of mountainous snowdominated basins and are usually sensitive to climate change at the regional scale (Rango and Martinec, 1994). Seasonal snow cover area is reduced due to the changing form of precipitation (from snow to rain) and rapid snow melting. Hydrological models are now increasingly used for predicting river responses under climate variability and change (Pechlivanidis et al., 2011). Derivation of a quantitative estimate of the snow-cover can be used to estimate snowmelt runoff. Snow-coverage is a key input variable for a wide variety of snowmelt runoff models. Climate change can affect snow cover and subsequently alter the river runoff in spring and summer, which have great impact on the socioeconomic development, disturb the fragile ecosystems, and even cause frequent occurrence of drought/flood disasters. Therefore, it is of great significance to the local sustainable development to investigate the snow cover change (Martinec and Rango, 1989).

Depletion curves of snow-covered areas (SDCs) continuously indicate the gradual areal diminishment of the seasonal snow cover during the snowmelt season. Snow cover area, which is the main input for preparation of SDCs, can be effectively derived using remote sensing. Satellite remote sensing data are well accepted for monitoring the snow-covered areas over continuous space-time scales compared to the conventional in situ snow measurements. For measuring and 
observing snow cover area, a variety of space borne sensors with various spectral, spatial, and temporal resolutions are available.

Snow-covered area monitoring gains importance as the ratio of snowmelt runoff to the total annual flow increases with increase in snow covered area. Thus, the snow-covered area is an important variable for snowmelt runoff prediction. Satellite snow cover monitoring also serves for determining the duration of the snow cover, the areal water equivalent, as well as to evaluate the effect of a changed climate on snow conditions and runoff. For instance, Rango and Martinec (1997) evaluated the average areal water equivalent of the seasonal snow-cover on 1 April in the basin of the Rio Grande at Del Norte, Colorado using the LANDSAT periodical snowcover mapping. Many studies have evaluated the relationship between SCA and snowmelt depth (Gupta et al., 1982; Seidel et al., 1998; Singh and Bengtsson, 2003; Takeli et al. 2005; Stewart, 2009).

Remote sensing technology provides an extremely important advantage for snow cover monitoring (Gafurov and Bárdossy, 2009). Many studies relating to the application of MODIS snow product in mapping SCA have been conducted in the recent years. MODIS snow products are most commonly used for snow cover mapping as they are produced on a daily basis and can be downloaded for free. Its $500 \mathrm{~m}$ spatial resolution results into high accuracy in comparison to ground information. These snow products have been evaluated for accuracy in many studies, either compared with ground based observations (Tekeli et al., 2005; Parajka and Blosch,
2006; Liang et al., 2008) or with the images derived from other sensors such as Landsat (Klein et al., 1998a; Maurer et al., 2003). MODIS products were observed to be acceptably accurate in the studies. MODIS snow cover product have been extensively used for generating snow cover maps and analysing its spatial and temporal variability all around the globe (Sirguey et al. 2009; Zhang et al. 2010; Jain et al. 2011; Paudel and Andersen, 2011; Rittger et al., 2013; Sarkar, 2015; Tahir et al., 2015; Gurung et al., 2017).

The present study has been undertaken to understand the average accumulation and depletion pattern of a snowcovered basin in the eastern Himalayan region. The study has also revealed the changes in depletion pattern under different projected climatic scenarios for future years. Section 2 introduces the study area and data, whereas the methodology is presented in Section 3. Section 4 presents the results of the analyses, followed by Conclusions in Section 5 .

\section{Study area and data}

The Mago basin (Fig. 1) with an upstream area of $839 \mathrm{~km}^{2}$ and located in the Tawang district of Arunachal Pradesh, India, was selected as the study area. The Central Water Commission (CWC) observatory, situated at the outlet of the Mago basin, was selected as the meteorological site. The snow starts accumulating in October and ends in March. Snow melt starts in February and continues up to June. Therefore, for the study basin, the period from February to June is considered as the ablation season.

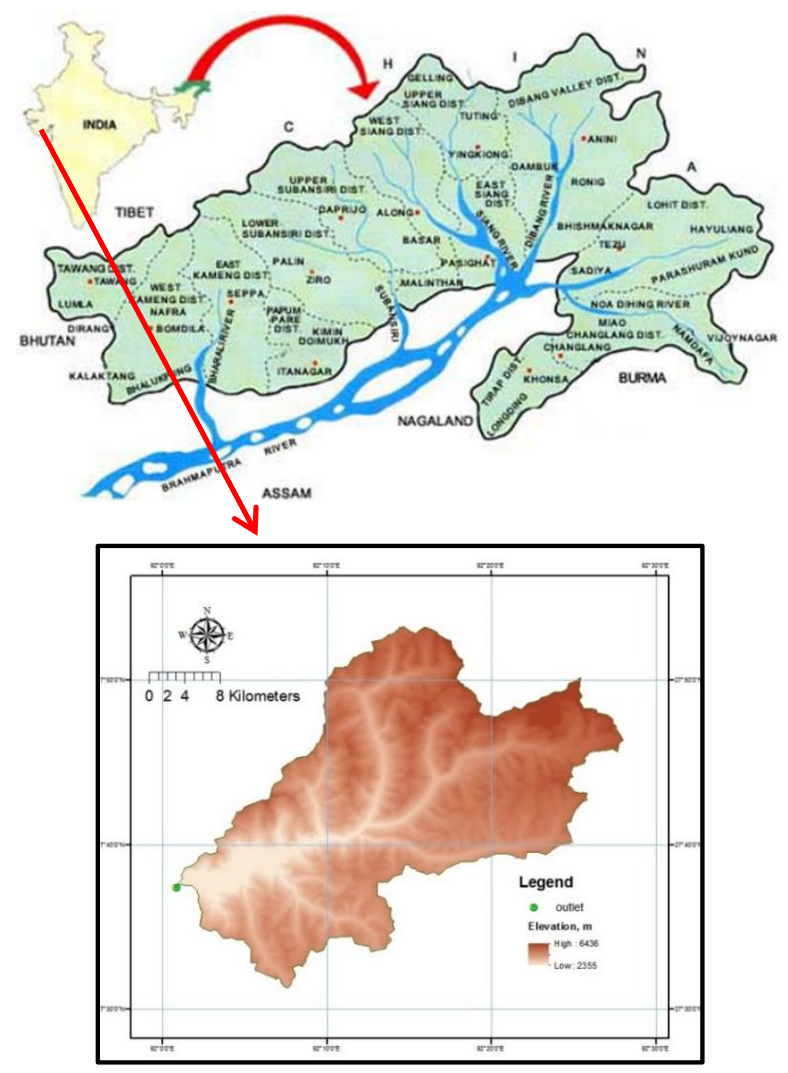

Figure 1. The Mago basin in Arunachal Pradesh, India 


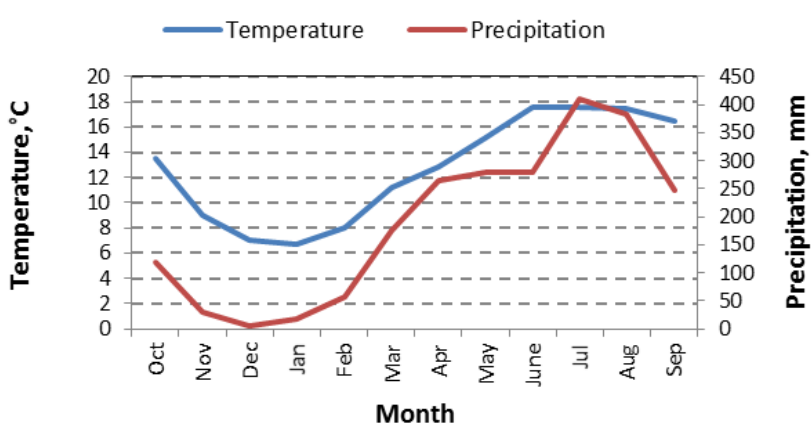

Figure 2. Average monthly mean temperature and total precipitation

MODIS daily snow cover images from both the Aqua (MYD10A1) and Terra (MOD10A1) satellites were downloaded from NASA's Distributed Active Archive Centre (DAAC) (http://reverb.echo.nasa.gov/reverb/). MOD10A1 and MYD10A1 for the period 2003-2013 were downloaded to obtain temporal distribution of SCA. Daily meteorological data (temperature and precipitation) at the CWC's site at China Bridge were collected for the period 2004-2013. The 10-year average temperature and precipitation data (Fig. 2) show that during January-February the temperature is lowest and then increases till mid-August, while monthly cumulative precipitation attains its peak in July. Both of them have a great impact on the snow-cover depletion pattern. Moreover, projected temperature and precipitation data were downloaded from NCAR's portal (https://gisclimatechange.ucar.edu/) for different emission scenarios (A1B, A2, B1, and IPCC commitment scenario; Nakicenovic et al., 2003; Girod et al., 2009) and future years (2020, 2030, 2040 and 2050) (Collins et al., 2006).

The degree-day factor $(a)$ can be estimated from daily decrease in snow water equivalent (SWE) per degree increase in degree-days. SWE is the snow water content of the snow pack. Average of maximum and minimum temperatures of a particular day refers to degree-days $(T)$ of that particular day. SWE of new snow is less and it increases as the snow pack ripens. As a result, the degree-day factor is subject to the melting season. The degree-day factor does not remain constant throughout the melting season, and different values for different months were assumed in this study (WMO, 1964). The critical temperature, which decides whether the precipitation during the snowmelt season is snow or rain, was set to $1.0^{\circ} \mathrm{C}$ for the year 2007 following the recommendation of Senzeba et al., (2015). The near surface temperature lapse rate was taken as $0.5^{\circ} \mathrm{C} / 100 \mathrm{~m}$ following the findings of Bandyopadhyay et al., (2014) for Arunachal Pradesh. The Digital Elevation Model (DEM) for the study area was downloaded from NASA's website (http://reverb.echo.nasa.gov/reverb/).

\section{Methodology}

\subsection{MODIS snow cover}

The MODIS snow cover algorithm is based on the high reflectance of snow in the visible band (band 4, 0.545- 0.565 $\mu \mathrm{m}$ ) and low reflectance in the near infrared band (band 6 , $1.628-1.652 \mu \mathrm{m})$. These two bands are used to calculate the normalized difference snow index (NDSI) (Hall et al., 1995). Normalized Difference Snow Index (NDSI) is calculated as:

$$
\text { NDSI }=\frac{\text { Band 4-Band } 6}{\text { Band 4+Band } 6}
$$

NDSI has been applied widely to optical imagery to discriminate snow from other targets. The detailed algorithm and processing steps have been documented in several sources (Hall et al., 2002; Riggs et al., 2006).

\subsection{Pre-processing of MODIS daily snow cover data}

Native MODIS data files are stored in a HDF-EOS (Hierarchical Data Format - Earth Observing System), a file format that does not currently have wide support. The MODIS Reprojection Tool (MRT) was used to convert HDF-EOS data format to GeoTIFF format. The downloaded HDF-EOS files served as input to the MRT. The MRT was downloaded from https://lpdaac.usgs.gov/tools/modis_reprojection_tool.

Using ERDAS IMAGINE 2011 all the converted GeoTIFF files were subset for the study area. Clipped MOD10A1 and MYD10A1 images were compared to select a cloud free image or minimum cloud image. This particular operation was achieved using the histogram utility available in the ERDAS IMAGINE 2011.

\subsection{Rectification of temperature and precipitation data}

From the DEM, an area-elevation (hypsometric) curve was generated (Fig. 3). The mean hypsometric elevation $(\bar{h})$ of the basin was found to be $4641 \mathrm{~m}$. Temperature data, measured at the meteorological station of CWC, China Bridge, were adjusted by temperature lapse rate up to mean hypsometric elevation of the basin. In the absence of long-term meteorological data, the year 2007 was selected to study the effect of climate change under different projected scenarios on SDC, since the monthly average temperature variation of 2007 matched well with the 10-year average temperature data recorded at CWC, China Bridge (Fig. 4). In 2007, the lowest temperature was found in the months of JanuaryFebruary, which is the same as in case of 10 -year average data.

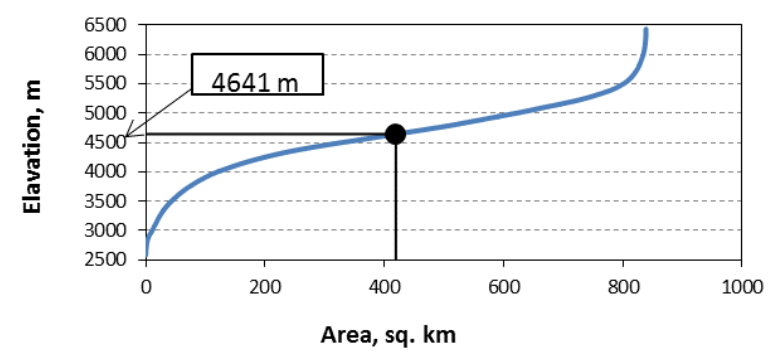

Figure 3. Area-elevation (hypsometric) curve 


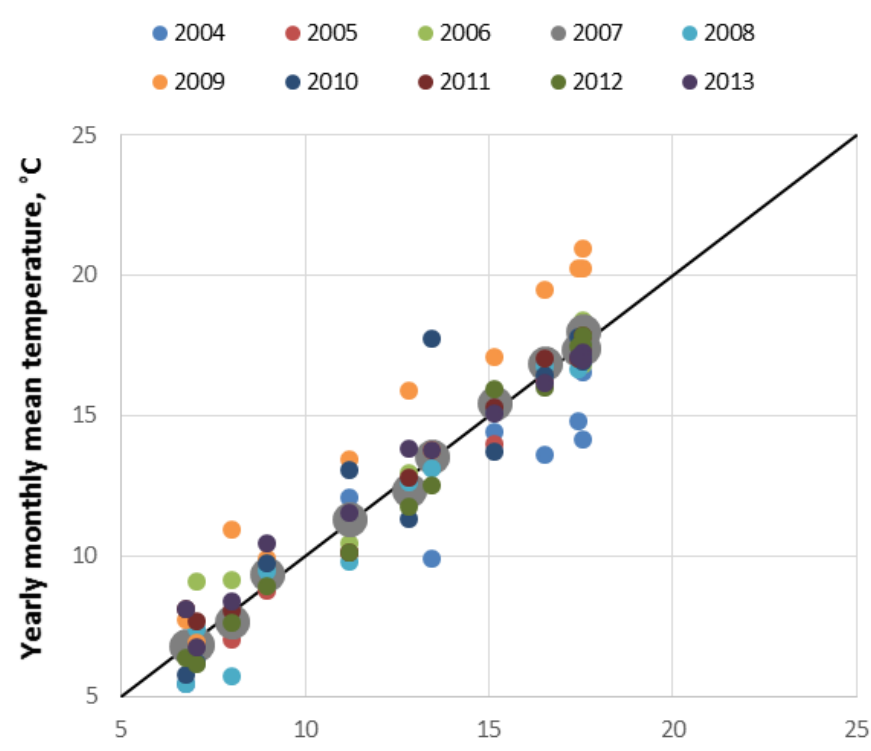

10 -year average monthly mean temperature, ${ }^{\circ} \mathrm{C}$

Figure 4. Yearly temperature variation with respect to 10-year average

The temperature and precipitation data for the selected 2007 hydrological year were rectified to represent the present climatic condition so that the impact of yearly fluctuation of temperature and precipitation on the snow-cover depletion can be eliminated (Martinec et al., 2008). The deviations of monthly average temperature of the year 2007 from 10-year means of monthly average temperature were determined by:

$$
\Delta \mathrm{T}=\overline{\mathrm{T}}_{\text {year }}-\mathrm{T}_{10 \text {-year average }}
$$

where $\overline{\mathrm{T}}_{\text {year }}$ is the mean monthly temperature of 2007 , and

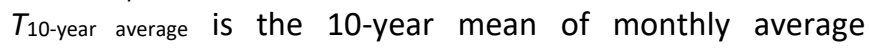
temperature for 2004-2013 for the corresponding month.

Then, the daily temperatures of the selected hydrological year 2007 were rectified/ adjusted with monthly fluctuations preserved as:

$$
\mathrm{T}_{\text {norm }}=\mathrm{T}_{\text {year }}-\Delta \mathrm{T}
$$

where $T_{\text {year }}$ is the daily temperature of the selected hydrological year 2007.

Ratios of long term monthly mean precipitation for 20042013 to the monthly mean precipitation of the year 2007 was determined by:

$$
r=\frac{\bar{P}_{\text {(10-year average) }}}{\bar{P}_{\text {year }}}
$$

where $\bar{P}$ is the mean monthly precipitation and $\mathrm{P}_{10}$-year average is the 10-year average monthly precipitation for 2004-2013 for the corresponding month.
The normalized/ rectified precipitation value was obtained by adjusting the daily precipitation of the selected hydrological year 2007 with monthly fluctuations preserved as:

$$
P_{\text {norm }}=P_{\text {year. }} r
$$

where $P_{\text {year }}$ is the daily precipitation for the selected hydrological year 2007.

Snowmelt depth was obtained by multiplying the degreedays ( $\left.T_{\text {norm}}\right)$ by degree-day factor $(a)$ as below:

$$
\text { Snowmelt depth }=T_{\text {norm }} \times \text { a }
$$

where $a$ is the degree day factor $\left(\mathrm{cm}^{\circ} \mathrm{C}^{-1}\right)$.

The decline of snow-cover extent not only depends on the initial snow reserve but also on the climatic conditions of the year being considered, since the amount and period of new snow falling during the snowmelt season varies year to year.

\subsection{Development of climate-affected depletion curve}

In this study, different projected climatic scenarios (A1B, A2, $B 1$, and IPCC Commitment) were considered for future years of 2020, 2030, 2040, and 2050. The use of different scenarios allows for the estimation of uncertainty of future impacts (Pechlivanidis et al., 2015; 2016a; 2016b). The Intergovernmental Panel on Climate Change (IPCC) SRES (Nakicenovic and Swart, 2000) describes that projected scenarios are the product of very complex dynamic systems, determined by driving forces such as demographic development, socio-economic development, and technological change. The main characteristics of A1B 
scenario include low population growth, very high gross domestic product (GDP), very high energy use, low-medium land use changes, medium resource (mainly oil and gas) availability, rapid pace and direction of technological change favoring balanced development. The B1 scenario includes low population growth, high GDP growth, low energy use, high land use changes, low resource (mainly oil and gas) availability, medium pace and direction of technological change favoring efficiency and dematerialization. The A2 scenario includes high population growth, medium GDP growth, high energy use, medium-high land use changes, low resource (mainly oil and gas) availability, slow pace and direction of technological change favouring regional economic development. The IPCC commitment scenario assumes that the temperature and precipitation will be restored to normal condition (present condition) within some years. This scenario is a non-SRES scenario (new constantconcentration commitment scenario that assumes concentrations are held fixed at year 2000 levels). In this idealised scenario, models are initialised from the end of the simulations for the 20th century, the concentrations of radiatively active species are held constant at year 2000 values from these simulations, and the models are integrated to 2100 (Solomon et al., 2007).

Cumulative snowmelt depth in present climate was obtained by multiplying the normalized temperature with a degree day factor (a). This snowmelt includes both the snow from the snowfall season and the climate induced snowfall or the new snowfall due to the climatic condition during the snowmelt season. Snow melt depth excluding new snowmelt depth was obtained by subtracting the cumulative value of new snow melt depth obtained by considering the effect of air temperature and precipitation from the cumulative snow melt depth in present climate. When the temperature at a particular day in the depletion period was lower than the critical temperature (in here $1.0^{\circ} \mathrm{C}$ ), the precipitation for the corresponding day was considered as new snow and it contributed to the snowmelt depth for the next day when temperature exceeded the critical temperature. The snowmelt depth was calculated from the degree-day factor (a) and the degree-days ( $T_{\text {norm }}$ ) corresponding to the next day. The modified depletion curve of the snow cover area for the changed climate (MDC CLIM) was obtained taking into account the amount of snowfall changed by the new climate. The shifting of dates for the climate-affected snow-cover depletion curves for 2020, 2030, 2040, and 2050 were determined following the analysis by Rango and Martinec, (1994) and Martinec et al., (2007) which is based on the cumulative snowmelt depth. The value of the modified depletion curve of snow covered area for a changed climate (MDC сци) was compared with the value of the cumulative snowmelt depth due to a changed climate obtained by multiplying the climate affected temperature with the degree day factor (a). If the value of the cumulative snowmelt depth due to climate change was equal to or greater than the first value of $\mathrm{MDC}_{\mathrm{CLIM}}$, it was taken as day 1 till the former value became less than the latter. If the cumulative snowmelt depth due to climate change was less than $\mathrm{MDC}_{\mathrm{CLIM}}$, then the same value of MDC CLIm was compared with the succeeding values of climate-affected cumulative snowmelt depth and in this case, the day was jumped whenever climate-affected cumulative snowmelt depth value was less than MDC cum. Climate-affected depletion curves were generated by plotting the daily value of SCA\% (from CDC) against these shifted dates. These curves indicate the change in the duration of depletion, its start and end time, and change in the rate of depletion under projected climatic scenarios.

In this study, it was attempted to derive the effect of climate change on the depletion curves in the years 2020, 2030, 2040 and 2050 under four projected climatic scenarios (A1B, IPCC Commitment, $\mathrm{A} 2$ and $\mathrm{B} 1$ ) to understand the change on a decadal basis.

\section{Results and discussion}

\subsection{Analysis during the present conditions}

Daily SCA and Cloud Cover Area percentages of the basin were determined from MODIS images. The images having cloud cover area percentages more than 5\% were not considered for the study. For cloud free dates, fifteen days average SCA\% values for each month were calculated and these average SCA\% values were plotted against respective months to generate snow accumulation and depletion pattern of the area.

Variations of SCA\% in accumulation as well as ablation months (October-June) were determined for ten snow-years from 2003 to 2013 (Fig. 5). During winter months, the monthly average temperature decreased from November till January-February and increased again up to July. Variations of SCA\% for individual snow-years also followed this unique trend of temperature. It can be observed from Fig. 5 that in most of the snow-years, two peaks have been observed in the SCA\% plots from October to June. The first smaller peak was observed in November (occasionally October) and the second peak, usually higher than the first one, occurred in February or March. From ten snow accumulation and depletion curves, the average snow accumulation and depletion pattern of the basin was obtained (Fig. 5) which also followed the same trend. Two peaks were obtained for the average snow cover curve, one small peak in November and another peak higher than the first one in March. The maximum snow cover area was obtained is $67.77 \%$ of the total study area in March. As per average curve, the snow depletion started in March and ended in June.

The conventional depletion curve $(C D C)$ representing present climate was derived by determining and interpolating the SCA percentages from MODIS satellite images having cloud cover of $5 \%$ or less for ablation period of year 2007. Fig. 6 shows the conventional depletion curve of the basin for the selected hydrological year (2007). The curve shows that the SCA\% is highest in the February and lowest in May, which can be correlated with the mean monthly temperature that 
reaches its lowest value in January and increases again until June.

\subsection{Changes under future conditions}

Fig. 7 shows the cumulative snowmelt depth curves of the basin during the ablation period under present climate and different projected climatic scenarios in the future. It can be observed from Fig. 8 and Table 1 that the cumulative snowmelt depth at the end of the ablation period (selected as the $3^{\text {rd }}$ of May) is expected to increase from the present climatic condition $(27.89 \mathrm{~cm})$ under all projected climatic scenarios (except for IPCC Commitment in 2050). Change in the cumulative snowmelt depth for different years in the future is maximum under $A 1 B$ and minimum under IPCC
Commitment scenarios. Changes corresponding to $A 2$ and $B 1$ are in-between $A 1 B$ and IPCC Commitment scenarios. These patterns can be related to projected temperature changes in future years, which are higher under A1B, lower under IPCC Commitment and in-between these two extremes for $A 2$ and $B 1$ in all future years. Consequently, high values of cumulative snowmelt depths are noticed under A1B, A2 and B1 scenarios due to higher temperature in these scenarios compared to present. Whereas for IPCC Commitment scenario, which assumes that the temperature and precipitation will be restored to present condition within some years, it is observed that the cumulative snowmelt depth decreases with advancement of years and becomes less than the present condition in 2050.

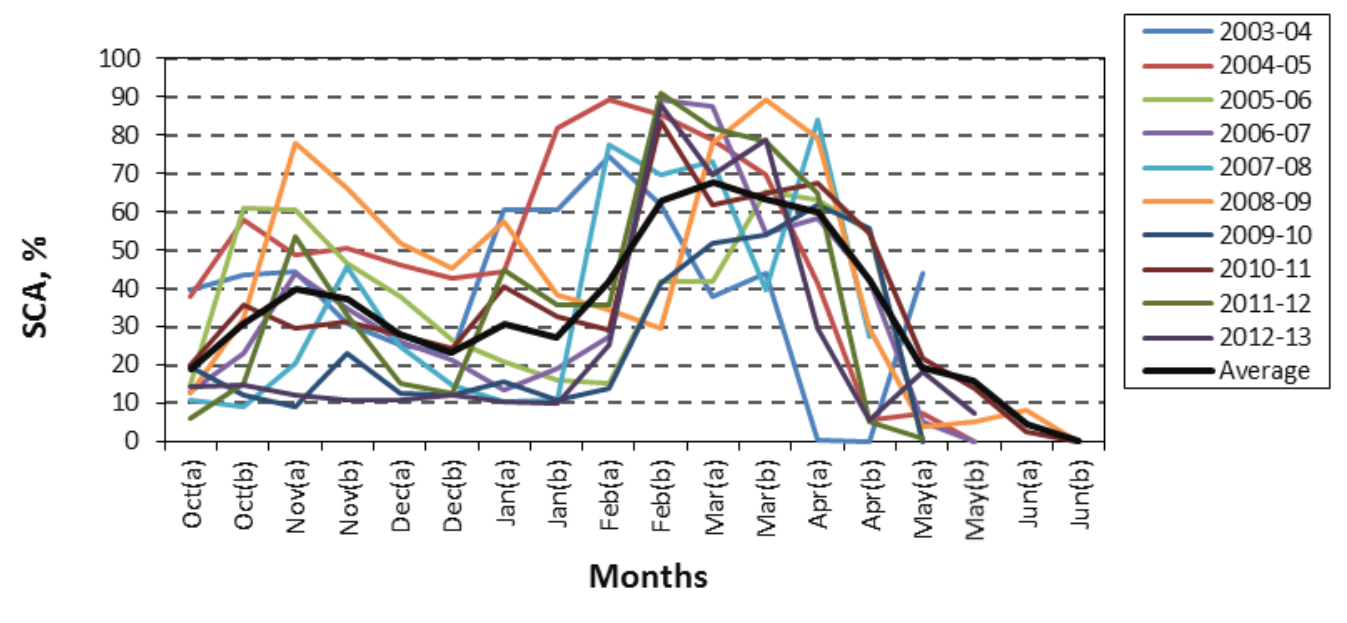

Figure 5. Accumulation and depletion patterns for different snow years ( $a=$ first fortnight, $b=$ second fortnight of $a$ month). The black solid line depicts the average distribution

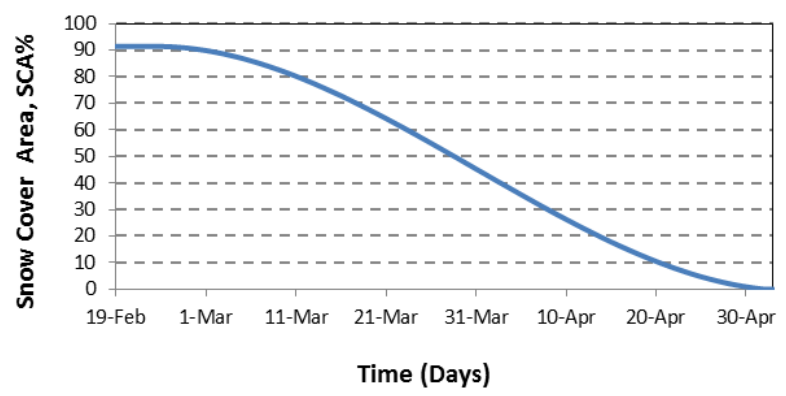

Figure 6. Conventional depletion curve

The CDC for the basin along with climate affected depletion curves computed for different projected climatic scenarios in the future are shown in Fig. 9. It can be inferred that the A1B climatic scenario affects the snow-cover depletion most. As a result, the depletion of snow completes faster in this scenario. Climate affected depletion curves under $A 2$ and $B 1$ scenarios are in-between A1B and IPCC Commitment scenarios. Compared to present climate, the shift of the ending date of the snow-cover depletion under different projected climatic scenarios in future years are presented in Table 2. It also shows the change in length of snow-cover depletion period leading to change in the depletion rate. For all future years, depletion completes with the fastest rate under A1B scenario, as change in temperature compared to present condition is the highest among the scenarios for all future years. On the other hand, the depletion period is the longest under IPCC scenario since increase in temperature for future years are minimum under this scenario for 2020, 2030 and 2040. In case of 2050, expected temperature under IPCC scenario is lower than the present temperature, therefore, depletion period is increased and depletion rate is decreased for the year 2050 under this scenario. It can be observed from Fig. 9 that, under all the climatic scenarios, acceleration was found to be high in the early and later part of the melt season in 2030 and 2040, while in the middle of the melt season, the depletion curve approximately followed the CDC. The faster depletion of snow in the basin may influence the total runoff distribution. In 2050, IPCC Commitment scenario resulted in a delayed start of snowmelt due to its lower than present temperature. 


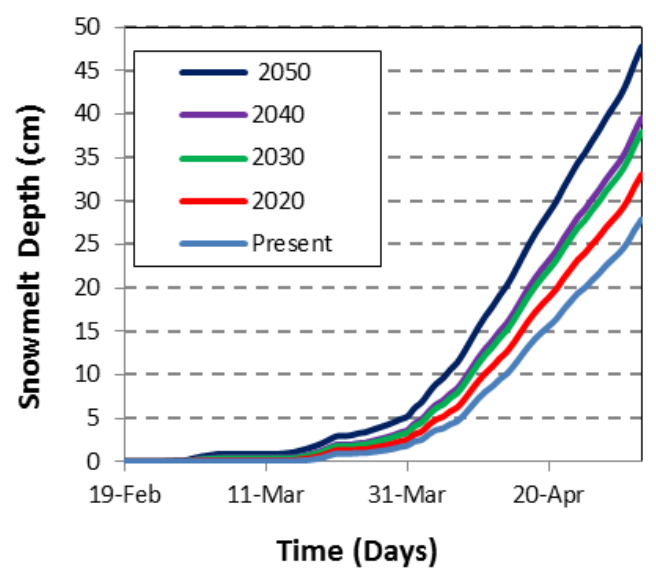

A1B

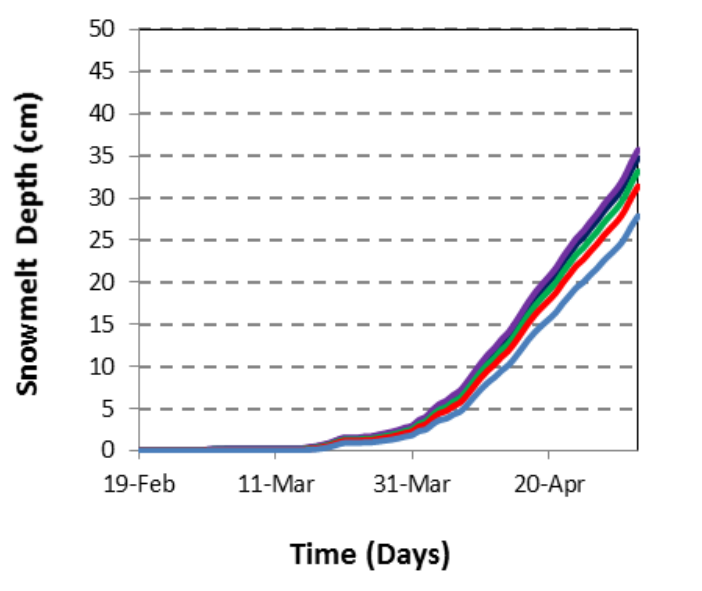

B1

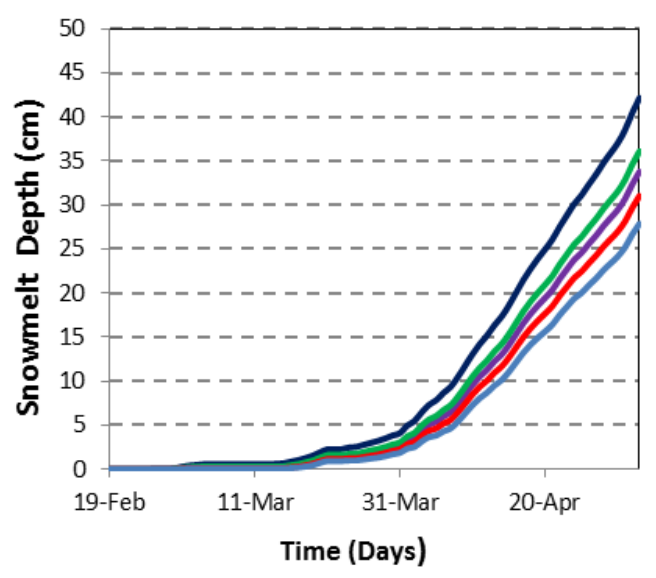

A2

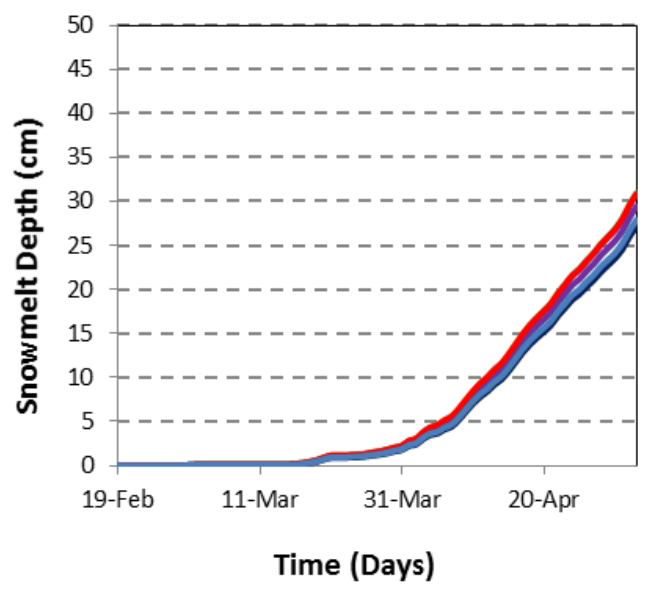

IPCC

Figure 7. Cumulative snowmelt depths for the future under different scenarios 


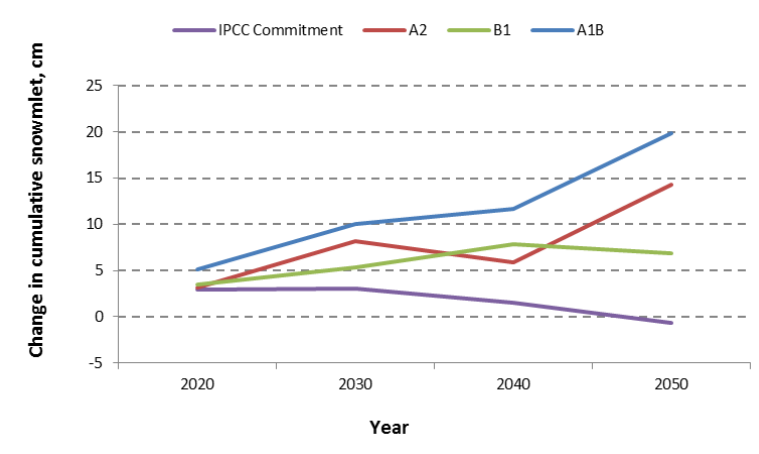

Figure 8. Change in cumulative snowmelt depth $(\mathrm{cm})$ on $3^{\text {rd }}$ May with respect to present climate

Table 1. Change in cumulative snowmelt depth $(\mathrm{cm})$ on $3^{\text {rd }}$ May with respect to present climate

\begin{tabular}{ccccc}
\hline Scenarios/Year & $\mathbf{2 0 2 0}$ & $\mathbf{2 0 3 0}$ & $\mathbf{2 0 4 0}$ & $\mathbf{2 0 5 0}$ \\
\hline A1B & 5.170 & 10.050 & 11.66 & 19.880 \\
\hline A2 & 3.159 & 8.223 & 5.905 & 14.288 \\
\hline B1 & 3.510 & 5.295 & 7.857 & 6.881 \\
\hline IPCC & 2.925 & 3.042 & 1.521 & -0.702 \\
\hline
\end{tabular}

Fig. 10 compares the number of shifted days for the ending date of the snow-cover depletion with the change in temperature over future under different projected climatic scenarios. The similar trend of the backward shift of end date and increase in temperature in all future years under all projected climatic scenarios is very apparent from Fig. 10. It is evident that the number of days of shifting in backward direction from present condition is higher when the corresponding change in temperature is higher and vice versa. For $\mathrm{A} 1 \mathrm{~B}, \mathrm{~A} 2$ and $\mathrm{B} 1$ scenarios, temperature is increasing for all future years, and hence the corresponding backward shifting in end date of depletion is also increasing. However under IPCC Commitment scenario, it is assumed that the temperature and precipitation will be restored to present conditions within some years, and therefore in this scenario, temperature is increasing marginally in 2020, 2030 and 2040 (with difference reducing every decade) but is below the temperature in 2050. Therefore, there is no backward shift in end date in 2040 and 2050 in this scenario. For any future year, backward shift in ending date of snow depletion is the highest under A1B and the lowest under IPCC Commitment scenarios, with $A 2$ and $B 1$ in-between them, following the same pattern as increase in temperature. Increase in the backward shift in end date of depletion means faster depletion. Fig. 11 shows the resulting increase in depletion rate from present rate in future years under different projected climatic scenarios. Increase in depletion rate with respect to present climate is highest under $A 1 B$ and lowest under IPCC Commitment scenarios, with A2 and B1 in-between them. As backward shift in end date is maximum under A1B scenario, the increase in depletion rate is also maximum under this scenario, whereas depletion rate is decreasing under IPCC scenario as the backward shift is decreasing for future years. The accelerated melting and the accelerated retreat of snowcovered area under A1B, A2 and B1 scenarios will have direct implications on snowmelt runoff volume and its distribution in time.

\section{Summary and conclusions}

In most of the snow-years, two peaks have been observed in the SCA\% plots from October to June for the Arunachal Pradesh basin. The first smaller peak is observed around Oct.-Nov. and the second peak, usually higher than the first one, occurs around Mar. - Apr. Change in the cumulative snowmelt depth for different future years is maximum under $\mathrm{A} 1 \mathrm{~B}$ and minimum under IPCC Commitment scenarios. The shift of ending date of the snow-cover depletion under different projected climatic scenarios shows that the length of snow-cover depletion period is reduced under all climatic scenarios for all future years thus increasing the depletion rate. It was observed that the A1B climatic scenario affected the depletion pattern most. As a result, the depletion of snow completes faster under A1B in future years while IPCC has the lowest effect on depletion curve having longest duration of snow depletion in 2050. Shifting of depletion curves for different future years are highest under $A 1 B$ and lowest under IPCC Commitment, $\mathrm{A} 2$ and $\mathrm{B} 1$ values are in-between $\mathrm{A} 1 \mathrm{~B}$ and IPCC Commitment. This shift of ending date of the snowcover depletion is found to be following a matching trend with change in temperature over future years under different projected climatic scenarios. Increase in depletion rate with respect to present climate is highest under $A 1 B$ and lowest under IPCC Commitment scenarios, with A2 and B1 in-between them. 


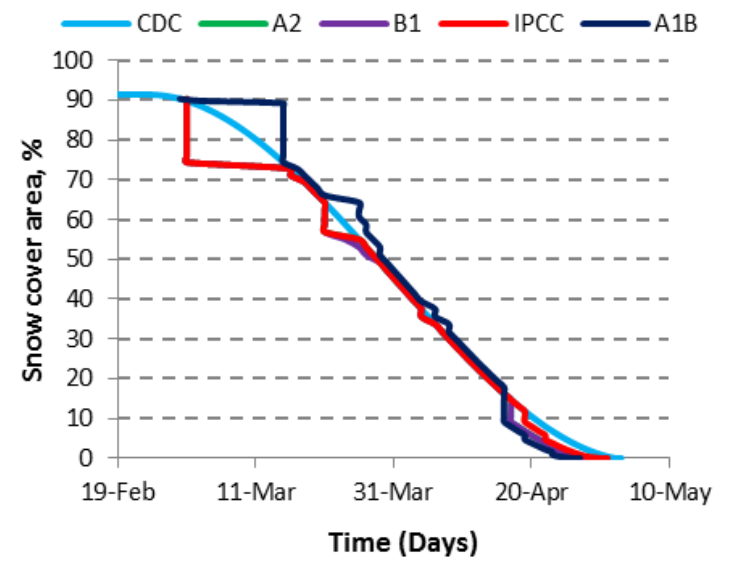

2020

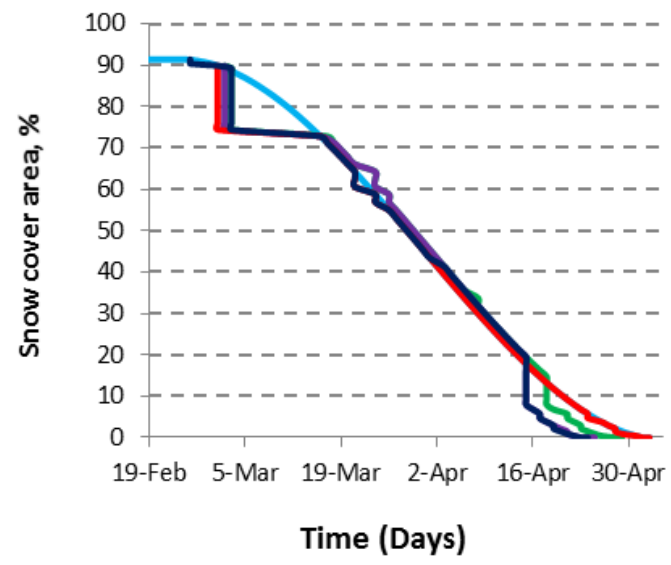

2040

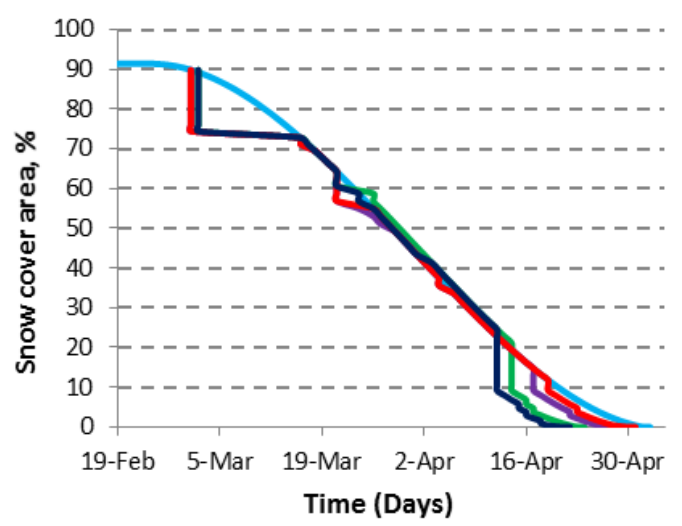

2030

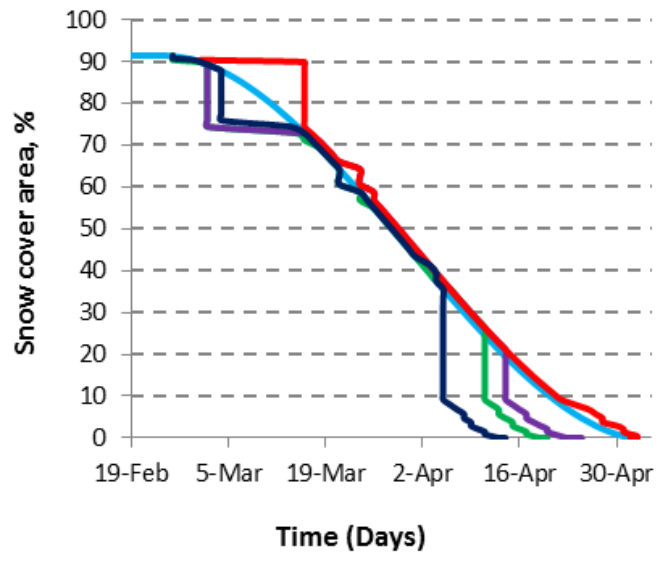

2050

Figure 9. Climate-affected depletion curves under projected climatic scenarios

Table 2. Change in depletion pattern over years for different climatic scenarios

\begin{tabular}{|c|c|c|c|c|c|c|c|c|c|}
\hline Year & Scenario & $\begin{array}{l}\text { Depletion } \\
\text { starts }\end{array}$ & $\begin{array}{c}\text { Backward shift in start } \\
\text { date, days* }\end{array}$ & $\begin{array}{l}\text { Depletion } \\
\text { completes }\end{array}$ & $\begin{array}{l}\text { Backward shift in } \\
\text { end date, days* }\end{array}$ & Duration, days & $\begin{array}{l}\text { Decrease in } \\
\text { duration, days }\end{array}$ & $\begin{array}{c}\text { Average } \\
\text { depletion } \\
\text { rate, } \\
\% d^{-1}\end{array}$ & $\begin{array}{c}\text { Change } \\
\text { in } \\
\text { depletion } \\
\text { rate, } \%\end{array}$ \\
\hline \multicolumn{2}{|c|}{ Present } & $25 \mathrm{Feb}$ & - & 3 May & - & 68 & - & 0.72 & - \\
\hline \multirow{4}{*}{2020} & A1B & $28 \mathrm{Feb}$ & -3 & $27 \mathrm{Apr}$ & 6 & 59 & 9 & 0.83 & 15.25 \\
\hline & $\mathrm{A} 2$ & $1 \mathrm{Mar}$ & -4 & $29 \mathrm{Apr}$ & 4 & 60 & 8 & 0.81 & 13.33 \\
\hline & B1 & $1 \mathrm{Mar}$ & -4 & $29 \mathrm{Apr}$ & 4 & 60 & 8 & 0.81 & 13.33 \\
\hline & IPCC & $1 \mathrm{Mar}$ & -4 & 1 May & 2 & 62 & 6 & 0.79 & 9.68 \\
\hline \multirow{4}{*}{2030} & A1B & $28 \mathrm{Feb}$ & -3 & $22 \mathrm{Apr}$ & 11 & 54 & 14 & 0.90 & 25.93 \\
\hline & $\mathrm{A} 2$ & $28 \mathrm{Feb}$ & -3 & $24 \mathrm{Apr}$ & 9 & 56 & 12 & 0.87 & 21.43 \\
\hline & B1 & $1 \mathrm{Mar}$ & -4 & $29 \mathrm{Apr}$ & 4 & 60 & 8 & 0.81 & 13.33 \\
\hline & IPCC & $1 \mathrm{Mar}$ & -4 & 1 May & 2 & 62 & 6 & 0.79 & 9.68 \\
\hline \multirow{3}{*}{2040} & A1B & $25 \mathrm{Feb}$ & 0 & $24 \mathrm{Apr}$ & 9 & 59 & 9 & 0.83 & 15.25 \\
\hline & $\mathrm{A} 2$ & 28 Feb & -3 & $29 \mathrm{Apr}$ & 4 & 61 & 7 & 0.85 & 11.48 \\
\hline & B1 & $28 \mathrm{Feb}$ & -3 & $25 \mathrm{Apr}$ & 8 & 57 & 11 & 0.80 & 19.30 \\
\hline \multirow{5}{*}{2050} & IPCC & $1 \mathrm{Mar}$ & -4 & 3 May & 0 & 64 & 4 & 0.76 & 6.25 \\
\hline & $A 1 B$ & 25 Feb & 0 & $14 \mathrm{Apr}$ & 19 & 49 & 19 & 0.99 & 38.78 \\
\hline & $\mathrm{A} 2$ & 25 Feb & 0 & $20 \mathrm{Apr}$ & 13 & 55 & 13 & 0.89 & 23.64 \\
\hline & B1 & 28 Feb & -3 & $25 \mathrm{Apr}$ & 8 & 57 & 11 & 0.85 & 19.30 \\
\hline & IPCC & $1 \mathrm{Mar}$ & -4 & 3 May & 0 & 64 & 4 & 0.76 & 6.25 \\
\hline
\end{tabular}

*minus indicates forward shift in dates 


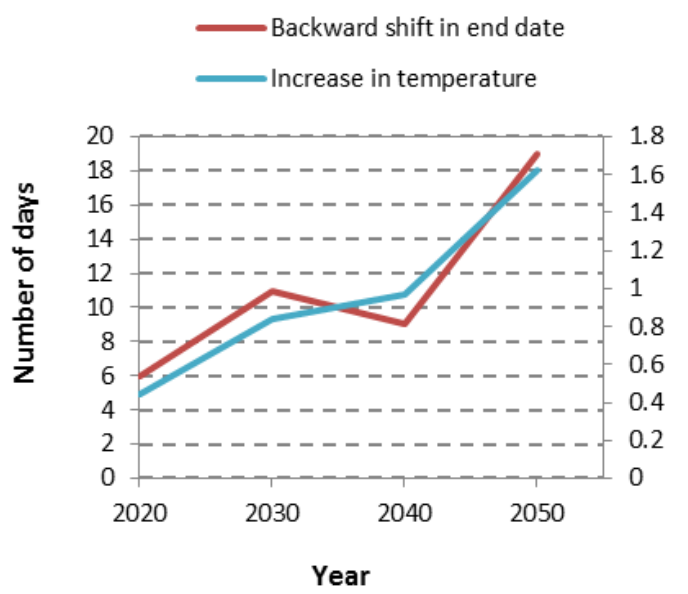

A1B

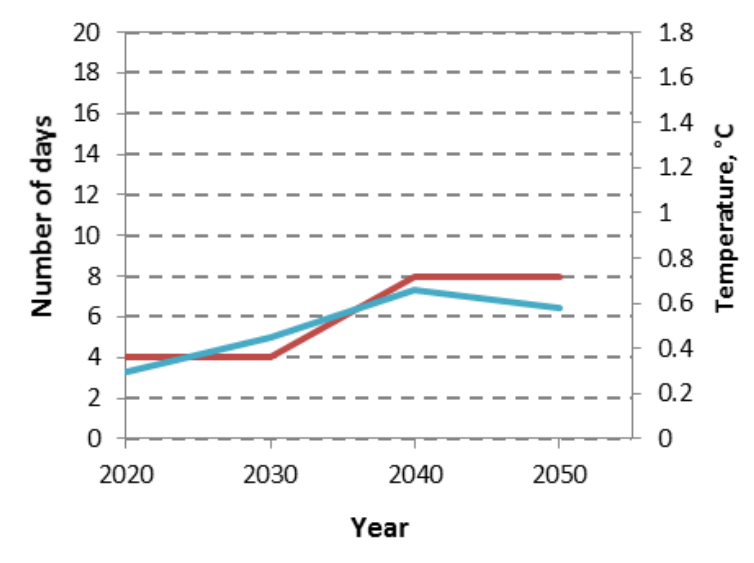

B1

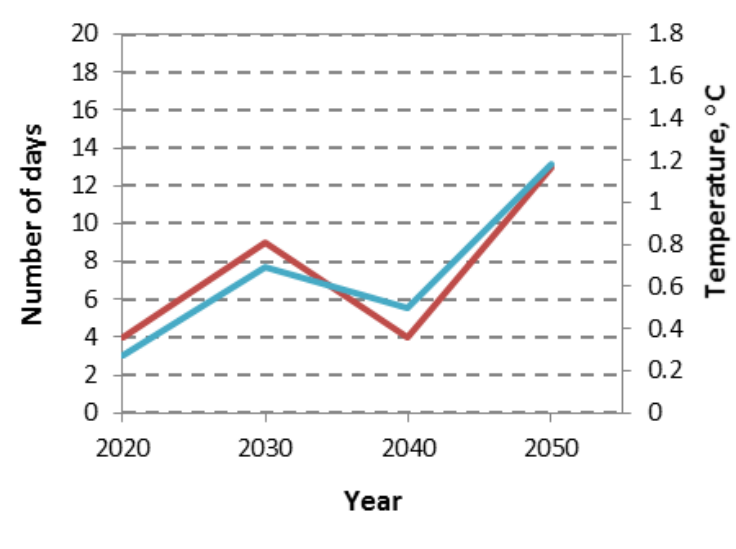

$\mathrm{A} 2$

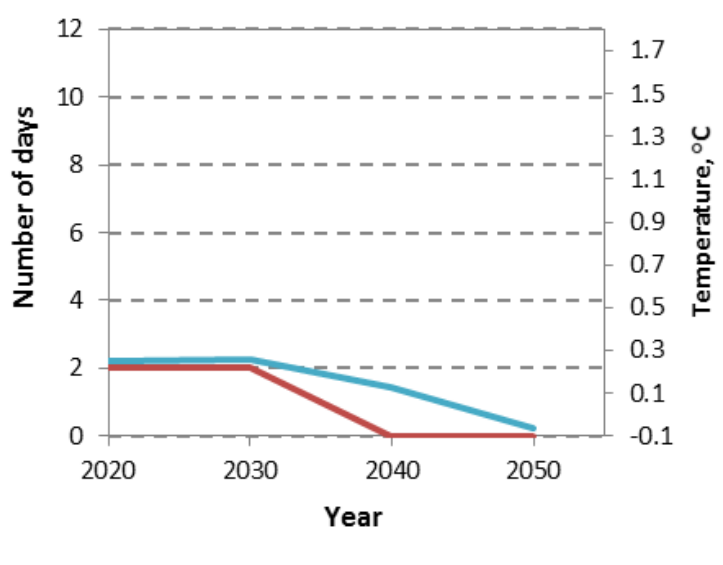

IPCC

Figure 10. Acceleration of depletion over years under different projected climatic scenarios

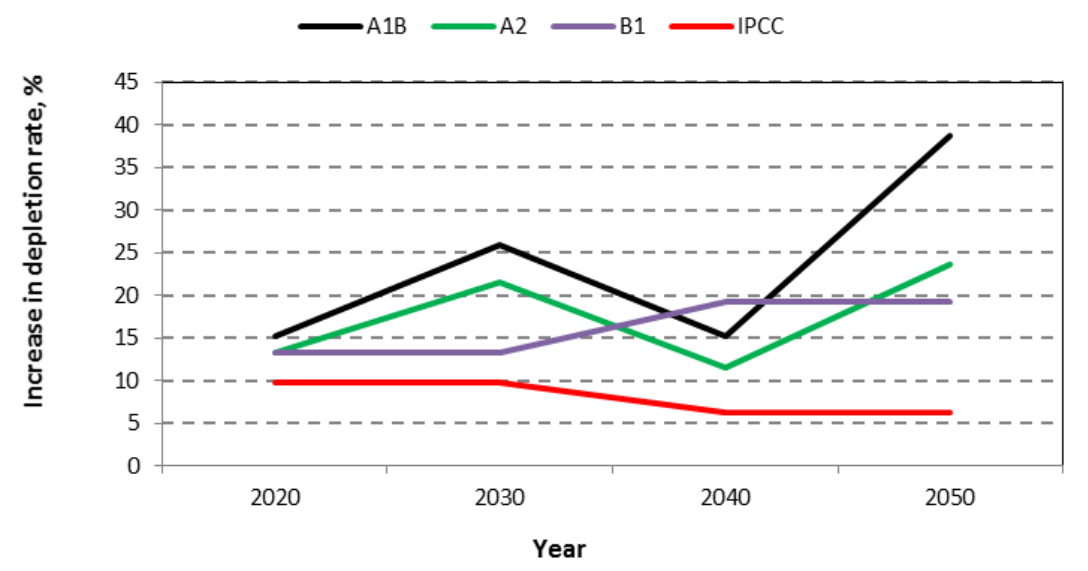

Figure 11. Change in depletion rate over years under different projected climatic scenarios

\section{References}

Bandyopadhyay A., Bhadra A., Maza M. and Shelina R.K. (2014), Monthly variations of air temperature lapse rates in Arunachal Himalaya, Journal of Indian Water Resources Society, 34(3), 16-25.
Collins W.D., Bitz C.M., Blackmon M.L., Bonan G.B., Bretherton C.S., Carton J.A., Chang P., Doney S.C., Hack J.J., Henderson T.B., Kiehl J.T., Large W.G., McKenna D.S., Santer B.D. and Smith R.D. (2006), The community climate system model version 3 (CCSM3), Journal of Climate, 19, 2122-2143. 
Gafurov A. and Bardossy A. (2009), Cloud removal methodology from MODIS snow cover product, Hydrology and Earth Systems Science, 13(7), 1361-1373.

Girod B., Wiek A., Mieg H. and Hulme M. (2009), The evolution of the IPCC's emissions scenarios, Environmental Science and Policy, doi:10.1016/j.envsci.2008.12.006.

Gupta R.P., Duggal A.J., Rao S.N., Sankar G. and Singhal B.B.S. (1982), Snow-cover area vs. snowmelt runoff relation and its dependence on geomorphology - A study from the Beas catchment (Himalayas, India), J. Hydrol., 58(3-4), 325-339.

Gurung D.R., Maharjan S.B., Shrestha A.B., Shrestha M.S., Bajracharya S.R. and Murthy M.S.R. (2017), Climate and topographic controls on snow cover dynamics in the Hindu Kush Himalaya, International Journal of Climatology, doi: $10.1002 /$ joc. 4961.

Hall D.K., Riggs A.G. and Salomonson V. (1995), Development of Method for Mapping Global Snow Cover using Moderate Resolution Imaging Spectroradiometer Data, Remote Sensing of Environment, 54(2), 127-140.

Hall D.K., Riggs G.A., Salomonson V.V., Digirolamo D.G. and Bayr K.J. (2002), MODIS snow-cover products, Remote Sensing of Environment, 83, 181-194.

Jain S.K., Thakural L.N., Singh R.D., Lohani A.K. and Mishra S.K. (2011), Snow-cover depletion under changed climate with the help of remote sensing and temperature data, Natural Hazards, 58, 891-904.

Khadka D., Babel M.S., Shrestha S. and Tripathi N.K. (2014), Climate change impact on glacier and snow melt and runoff in Tamakoshi basin in the Hindu Kush Himalayan (HKH) region, Journal of Hydrology, 511, 49-60.

Klein A.G., Hall D.K. and Riggs G. (1998a), Improving snow-cover mapping in forests through the use of a canopy reflectance model, Hydrological Processes, 12, 1723-1744.

Liang T.G., Huang X.D., Xia Wu C., Liu X.Y., Li W.L., Zheng G.G. and Ren J.Z. (2008), An Application of MODIS Data to Snow Cover Monitoring in a Pastoral Area: A Case Study in Northern Xinjiang, China, Remote Sensing of Environment, 112(4), 1514-1526.

Martinec J. and Rango A. (1989), Effects of climate change on snowmelts 357 runoff patterns, remote sensing and large scale global processes. In: Proc. of the Baltimore Symposium, IAHS Publ. no. 186: 31-38.

Martinec J., Rango A. and Roberts R. (2008), Snowmelt-Runoff Model (SRM) user's manual. USDA Jornada Experimental Range, New Mexico State University, Las Cruces, NM 88003, USA.

Maurer E.P., Rhoads J.D., Dubayah R.O. and Lettenmaier D.P. (2003), Evaluation of the Snow-Covered Area Data Product from MODIS, Hydrological Processes, 17(1), 59-71.

Nakicenovic N. and Swart R. (Eds.) 2000. Special report: Emissions scenarios. Intergovernmental Panel on Climate Change (IPCC). Cambridge University Press, UK.

Nakicenovic N., Grubler A., Gaffin S., Jung T.T., Kram T., Morita T., Pitcher H., Riahi K., Schlesinger M., Shukla P.R., Vuuren D.Y., Davis G., Michaelis L., Swart R. and Victor N. (2003), IPCC SRES Revisited: A Response, Energy and Environment, 14(2\&3), 187-214.

Parajka J. and Blosch G. (2006), Validation of MODIS Snow Cover Images over Austria, Hydrology and Earth Systems Sciences, 10, 679-689.
Paudel K.P. and Andersen P. (2011), Monitoring snow cover variability in an agropastoral area in the Trans Himalayan region of Nepal using MODIS data with improved cloud removal methodology, Remote Sensing of Environment, 115(5), 1234-1246.

Pechlivanidis I.G., Arheimer B., Donnelly C., Hundecha Y., Huang S., Aich V., Samaniego L., Eisner S. and Shi P. (2016b), Analysis of hydrological extremes at different hydro-climatic regimes under present and future conditions, Climate Change, doi: 10.1007/s10584-016-1723-0.

Pechlivanidis I.G., Jackson B., McIntyre N. and Wheater H.S. (2011), Catchment scale hydrological modelling: A review of model types, calibration approaches and uncertainty analysis methods in the context of recent developments in technology and applications, Global NEST Journal, 13(3), 193-214.

Pechlivanidis I.G., Olsson J., Bosshard T., Sharma D. and Sharma K.C. (2016a), Multi-basin modelling of future hydrological fluxes in the Indian subcontinent, Water, 8(177), 1-21, doi:10.3390/w8050177.

Pechlivanidis I.G., Olsson J., Sharma D., Bosshard T. and Sharma K.C. (2015), Assessment of the climate change impacts on the water resources of the Luni region, India, Global NEST Journal, 17(1), 29-40.

Rango A. and Martinec J. (1994), Areal extent of seasonal snowcover in a changed climate, Nordic Hydrol., 25, 233-246.

Rango A., Martinec J. (1997), Water storage in mountain basins from satellite snow-cover mapping. In: Baumgartner, M.F., Schultz, G.A., Johnson, A.I. (Eds.). Remote Sensing and Geographical Information Systems for Design and Operation for Water Resources System, IAHS Publ. no. 242: 83-91.

Riggs G.A., Hall D.K., Salomonson V.V. 2006. MODIS Snow Products User Guide Collection 5. http://modis-snowice.gsfc.nasa.gov/sugkc2.html.

Rittger K., Painter T.H. and Dozier J. (2013), Assessment of methods for mapping snow cover from MODIS, Advances in Water Resources, 51, 367-380.

Sarkar A. (2015), Impact of climate change on the runoff regime of an Eastern Himalayan river basin, Global NEST Journal, 17(2), 323-333.

Seidel K., Ehrler C. and Martinec J. (1998), Effects of climate change on water resources and runoff in an alpine basin, Hydrological Processes, 12(10-11), 1659-1669.

Senzeba K.T., Bhadra A. and Bandyapadhyay A. (2015), Snowmelt runoff modelling in data scare Nuranang catchment of eastern Himalayan region, Remote Sensing Applications: Society and Environment, 1, 20-35.

Singh P. and Bengtsson L. (2003), Effect of warmer climate on the depletion of snow-covered area in the Satluj basin in the western Himalayan region, Hydrological Sciences Journal, 48(3), 413-425.

Sirguey P., Mathieu R. and Arnaud Y. (2009), Subpixel monitoring of the seasonal snow cover with MODIS at $250 \mathrm{~m}$ spatial resolution in the Southern Alps of New Zealand: Methodology and accuracy assessment, Remote Sensing of Environment, 113(1), 160-181.

Solomon S., Qin D., Manning M., Chen Z., Marquis, M., Averyt, K.B., Tignor, M. and Miller, H.L. (Eds.). 2007. Climate change: The physical science basis. Contribution of working group I to the fourth assessment report of the Intergovernmental Panel on Climate Change (IPCC). Cambridge University Press, Cambridge, United Kingdom and New York, NY, USA. 
Stewart I.T. (2009), Changes in snowpack and snowmelt runoff for key mountain regions, Hydrological Processes, 23(1), 78-94.

Tahir A.A, Chevallier P., Arnaud Y., Ashraf M. and Bhatti M.T. (2015), Snow cover trend and hydrological characteristics of the Astore River basin (Western Himalayas) and its comparison to the Hunza basin (Karakoram region), Science of the Total Environment, 505, 748-761.

Tekeli A.E., Akyurek Z., Sormanc A.A., Sensoy A. and Sorman A.U. (2005), Using MODIS Snow Cover Maps in Modeling Snowmelt Runoff Process in the Eastern Part of Turkey, Remote Sensing of Environment, 97, 216-230.

WMO. 1964. Guide for hydrometeorological practices. WMO, Geneva, Switzerland.

Zhang Y., Yan Su. and Lu Yu. (2010), Snow Cover Monitoring Using MODIS Data in Liaoning Province, Northeastern China, Remote Sensing, 2(3), 777-793. 